\title{
Control of a Hydraulic Wind Power Transfer System under Disturbances
}

\author{
Masoud Vaezi, Afshin Izadian, Senior Member, IEEE \\ Energy Systems and Power Electronics Laboratory \\ Purdue School of Engineering and Technology, IUPUI \\ Indianapolis, IN, USA \\ aizadian@iupui.edu
}

\begin{abstract}
Hydraulic wind power transfer systems deliver the captured energy by the blades to the generators differently and through an intermediate medium i.e. hydraulic fluid. This paper develops a control system for a nonlinear model of hydraulic wind power transfer systems. To maintain a fixed frequency electrical voltage by the system, the generator should remain at a constant rotational speed. The fluctuating wind speed from the upstream applies considerable disturbances on the system. A controller is designed and implemented to regulate the flow in the proportional valve and as a consequence the generator maintains its constant speed compensating for low wind speed and high wind speed disturbances. The controller is applied to the system by utilizing MATLAB/Simulink.
\end{abstract}

Keywords-Renewable Energy; Wind Power systems; Hydraulic Transfer System; Control System.

\section{INTRODUCTION}

Renewable energies have recently received a great attention as an alternative to fossil fuels. Environmental issues, such as the excess amount of hydrocarbon in the air caused by fossil fuels, have compelled the researchers and engineers to look for new types of renewable energies as well as new ways to increase the efficiency of current renewable energy systems [1].

Wind power, as one of the most known and most considerable renewable energies, is the conversion of wind energy into a useful form of energy, such as using wind turbines to produce electrical power, windmills for mechanical power, wind pumps for water pumping or drainage, or sails to propel ships. Large wind farms consist of hundreds of individual wind turbines which are connected to an electric power transmission network. For new constructions, onshore wind is an inexpensive source of electricity, competitive with or in many places cheaper than fossil fuel plants. Offshore wind is steadier and stronger than on land. Offshore farms have less visual impact, but their construction and maintenance costs are considerably higher [2]. Small onshore wind farms can feed some energy into the grid or provide electricity to isolated off-grid locations. Wind power, as an alternative to fossil fuels, is plentiful, renewable, widely distributed, clean, produces no greenhouse gas emissions during operation and uses little land. The effects on the environment are generally less problematic than those from other power sources [3].

Wind energy generation systems have been improved over the last decade, but the high capital investments and low capacity factors have not been resolved to decrease the cost of the energy. Conventional wind farms consist of hundreds of wind towers, each of which is equipped with a gearbox and a generator located in a nacelle on top of the tower. Recent developments in hydraulic wind power transfer technology offer several advantages over conventional wind energy transfer technologies [4].

Hydraulic wind power transfer (HWPT) systems are new generation of wind turbines which have recently drawn the researcher's attention. Fig. 1 illustrates the schematic of HWPT systems. In these systems, the energy captured by the wind turbine's blades are transferred to the generator differently. Rather than utilizing a gearbox connected to the generator in nacelle, a hydraulic circuit transfers the captured energy. The implemented pump which is connected directly to the blade's shaft, pressurize a hydraulic fluid down on the ground through hoses [5-7]. A proportional valve in the way of the high pressure line distributes the flow between two hydraulic motors which are connected to the generators. Actuating the proportional valve by a robust controller, one can regulate the angular velocity of the primary motor in order to generate a fixed frequency power to feed the grid [8-10].

HWPT systems introduce several advantages over the conventional systems. First, these systems replace the bulky gearbox, power electronics and the generator in the nacelle with a single pump. This replacement will reduce a great amount of implementation and maintenance cost. Moreover, the design of the hydraulic circuit in HWPT system allows for generation of fixed frequency electricity power without utilizing power electronics. This benefit will considerably shrink the capital costs and operation costs [11]. Finally, the flexibility of hydraulic circuits will offer a new configuration for wind farms. In this new configuration, a single generator can be utilized for multiple wind turbines rather than implementing one generator for one wind turbine in conventional wind farms. In Addition, the generator used in

This is the author's manuscript of the article published in final edited form as: Vaezi, M., \& Izadian, A. (2014). Control of a hydraulic wind power transfer system under disturbances. In 2014 International Conference on Renewable Energy Research and Application (ICRERA) (pp. 886-890). http://doi.org/10.1109/ICRERA.2014.7016512 
HWPT systems can be located on the ground which is of high importance to decrease the capital and operation cost [12].

This paper is focused on understanding the operation of the hydraulic wind power transfer dynamics and also deigning a control system for it. The controller is designed and implemented to regulate the flow in the proportional valve and as a consequence the generator maintains its constant speed compensating for wind speed disturbances. The intermittent nature of wind speed disturbances greatly affects the desired outputs. Therefore, this is essential to study the system dynamic in order to compensate for disturbances through an accurately designed controller. Moreover, nonlinearities such as hysteresis in the proportional valve make the design of the control loop more challenging. Thus, the designed controller is required to address this behavior.

This paper is organized as follows: Section 2 explains the concept of the hydraulic wind energy transfer system with a schematic of the high-pressure hydraulic power transfer system. The nonlinear model of these systems is summarized in Section 3. Section 4 describes the designed control system for a hydraulic wind power transfer system. Finally, Section 5 discusses the results from the system and the performance of the controller.

\section{HYDRAULIC WIND ENERGY TRANSFER}

The hydraulic wind power transfer system is comprised of various parts such as hydraulic pumps and motors, proportional valves, check valves, and pressure relief valves. A prime mover (wind turbine blades) is utilized in this configuration to drive a fixed displacement pump. Also, to transmit the captured power, one or more fixed displacement hydraulic motors are employed. At the upstream, the implemented pump transforms the mechanical power from the blades' shaft to the pressurized fluid and then the captured energy is transferred to the hydraulic motors through hydraulic hoses and pipes $[13,14]$.

Wind power is harvested using a high-torque low speed turbine. Intermittent wind speed introduces hydraulic flow fluctuations from the prime mover that eventually changes the electric power flow in the system. Steady electric power generation requires steady flow of pressurized hydraulic medium to the main hydraulic motor. Proportional valves are used to regulate and control the hydraulic flow to manage the electric power generation. Fig. 1 depicts a schematic diagram of hydraulic wind power transfer systems [15].

A prototype is implemented as a test bed for hydraulic wind power transfer technology in the Energy Systems and Power Electronics Laboratory, IUPUI. Fig. 2 demonstrates an overlay of the experimental setup and hydraulic circuitry. An electric motor was used to drive the hydraulic pump through the pulley and belt to reduce the pump shaft speed. The system operating conditions, such as angular velocity and pressures, are precisely measured by fast prototyping in dSPACE 1104 hardware [16].

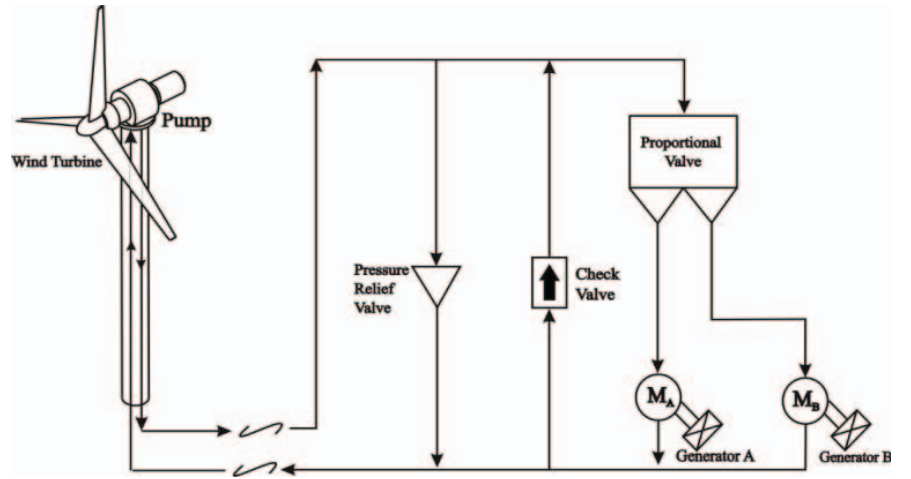

Figure 1. Schematic of hydraulic wind power transfer systems.

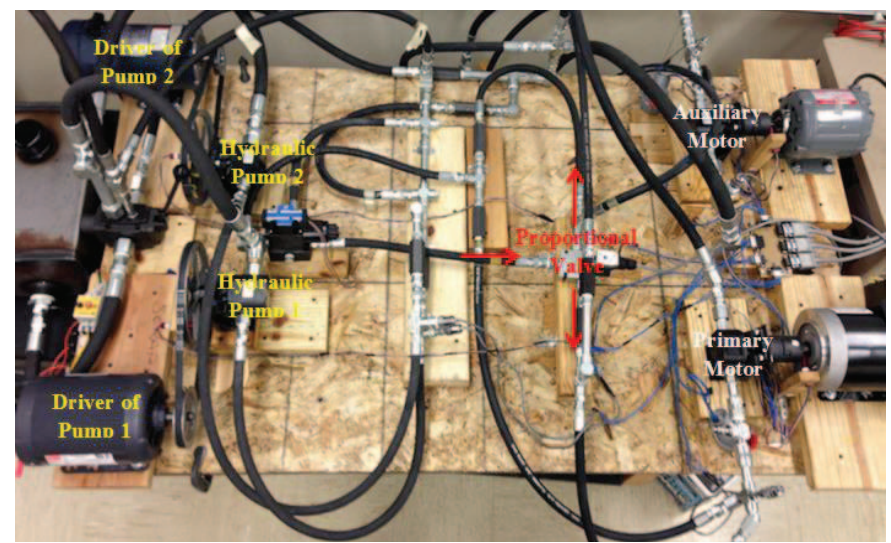

Figure 2. Experimental setup of the hydraulic wind power transfer system. Energy Systems and Power Electronics Laboratory.

\section{HydRAULIC WIND POWER SYSTEM MODEL}

Understanding the dynamics of the system through the mathematical modeling considerably helps to choose the best energy storage technique and related control system. To derive the state space representation of the hydraulic wind power system, the integrated configuration of the hydraulic components must be considered. Nonlinear governing equations of utilized hydraulic components are provided in [1719]. Using these equations, a nonlinear model of hydraulic wind power transfer systems are proposed in state space representation and experimentally verified. State space representation offers several benefits such as the ease of implementation, stability analysis, and model understanding [20-23].

In general, the nonlinear state space model of a system can be represented as

$$
\begin{aligned}
& \dot{x}=f(x)+g(x) U \\
& y=h(x)
\end{aligned}
$$

where $x$ is the state vector, $y$ is the output vector, $U$ is the input vector, $f(x)$ is an input independent function vector of the states, $g(x)$ is the input dependent function matrix of the state variables, and $h(x)$ is the output function. The state space model is achieved in [18] with states and inputs as follows: 


$$
x=\left[\begin{array}{lllll}
P_{p} & P_{m A} & P_{m B} & \omega_{m A} & \omega_{m B}
\end{array}\right]^{T}, \quad U=\left[\begin{array}{c}
h_{i} \\
\omega_{p}
\end{array}\right],
$$

where the inputs to the hydraulic system are $\omega_{p}$, the angular velocity of the hydraulic pump (wind speed), and $h_{i}$, the position of the proportional valve. The state variables are the pressure of the pump $\left(P_{p}\right)$, pressure of the Motor A $\left(P_{m A}\right)$, pressure of the motor $\mathrm{B}\left(P_{m B}\right)$, the primary motor angular velocity $\left(\omega_{m A}\right)$, and the auxiliary motor angular velocity $\left(\omega_{m B}\right)$ [24-28].

\section{CONTROL SYSTEM DESIGN}

It can be observed from the system configuration that even at constant flow the motor speed varies if the pressure fluctuates. The differential pressure variation, inlet flow fluctuation and motor pressure variation are source of disturbances on motor speed, so that an appropriate controller is required for the valve to compensate for these disturbances.

This section represents a control system for the hydraulic wind power transfer system model. The primary goal of the control system is to maintain a constant speed for primary motor under the disturbances such as low wind speed fluctuations and high wind speed fluctuations. The controller is challenged through two different control simulations. The controller performance is shown in primary motor speed regulation under wind disturbances. In each simulation, the response of the system is illustrated as well as all other states behavior during the run.

Addressing the primary goal of the design makes the control system single-input and single output (SISO). The control input to the system is a voltage profile to the proportional valve sent by the designed controller in MATLAB/Simulink. The more voltage is applied by the controller; the more flow deviates to the auxiliary motor. Also, the primary output of the system is the speed of primary motor. Finally, pump shaft speed is the disturbance input to the system.

A PI controller is designed based on Ziegler-Nichols method in order to satisfy performance indices considered for the system having the form of:

$$
u(t)=K_{p} e(t)+K_{i} \int_{0}^{t} e(t) d t
$$

where $\mathrm{k}_{\mathrm{p}}$ and $\mathrm{k}_{\mathrm{i}}$ are proportional and integral gain, respectively and $\mathrm{e}(\mathrm{t})$ is the error between desired output and system output. In Ziegler-Nichols method, studying the dynamic behavior of the system under the step input will result in PI gains. Utilizing the step response characteristic parameters of the system in Ziegler-Nichols method, PI gains are listed Table I.
TABLE I.

LIST OF PI GAINS

\begin{tabular}{cc}
\hline Gain & value \\
\hline Proportional & 0.00013 \\
\hline Integral & 0.002 \\
\hline
\end{tabular}

The gains in Table I are implemented in the PI controller in MATLAB/Simulink for further simulations in next sections.

\section{RESULTS AND DISCUSSION}

In this section, the controller performance is tested under fluctuations. The system starts in closed loop and during the simulation a step variation for pump speed is applied to the system. The controller actuates the proportional valve properly to compensate for applied wind disturbance.

\section{A. Control under Low Wind Speed Disturbances}

Fig. 3 depicts the pump speed fluctuations exerted to the control system. Regulation response of the system is shown in Fig. 4 and Fig. 5. Finally, Fig. 6 illustrates the control command applied to the proportional valve by the controller. As it can be seen, the controller works flawlessly under low wind speed disturbances.

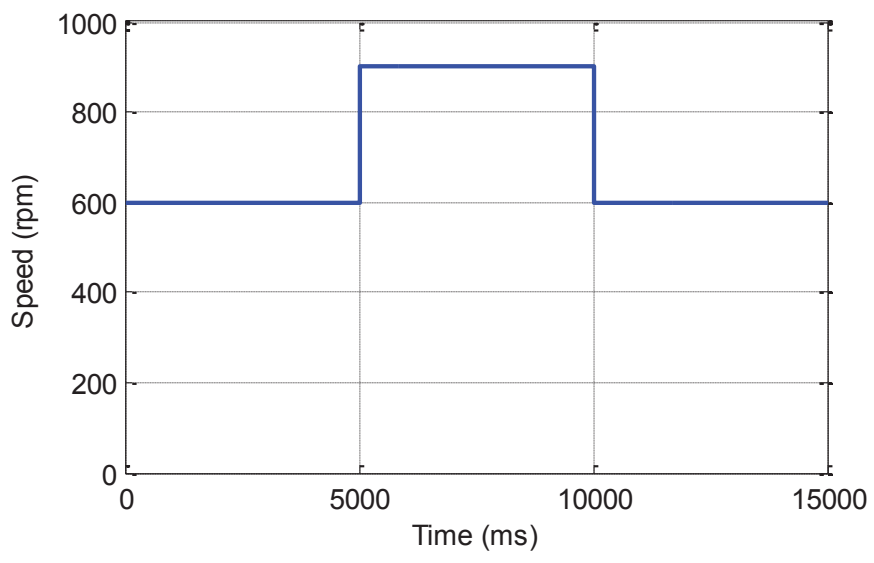

Figure 3. Pump speed variations applied to regulation under low wind speed disturbances.

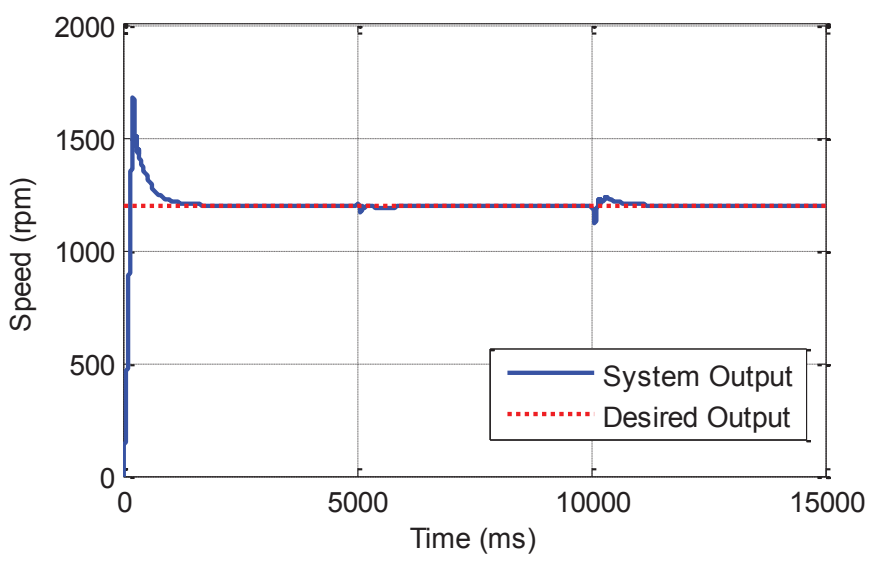

Figure 4. Regulation response of the system under low wind speed disturbances. 


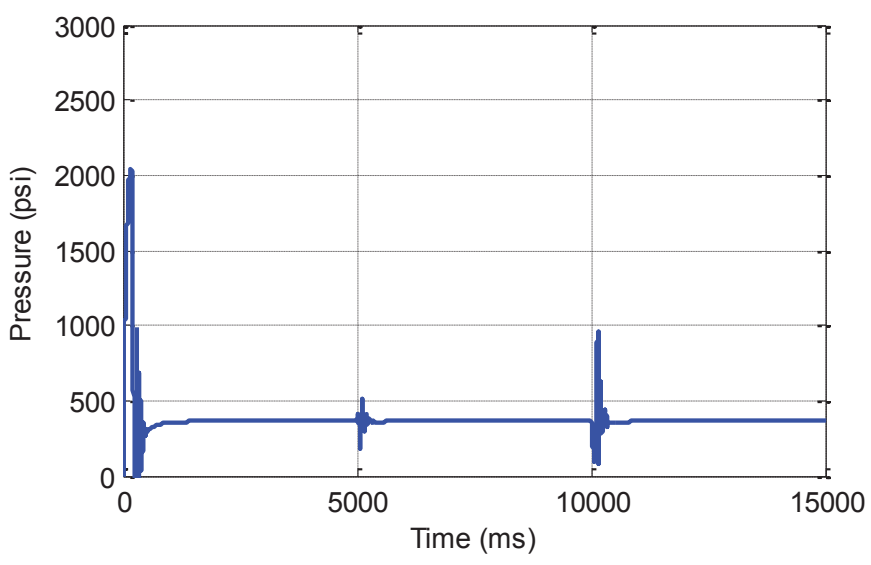

Figure 5. Motor A pressure in regulation under low wind speed disturbances.

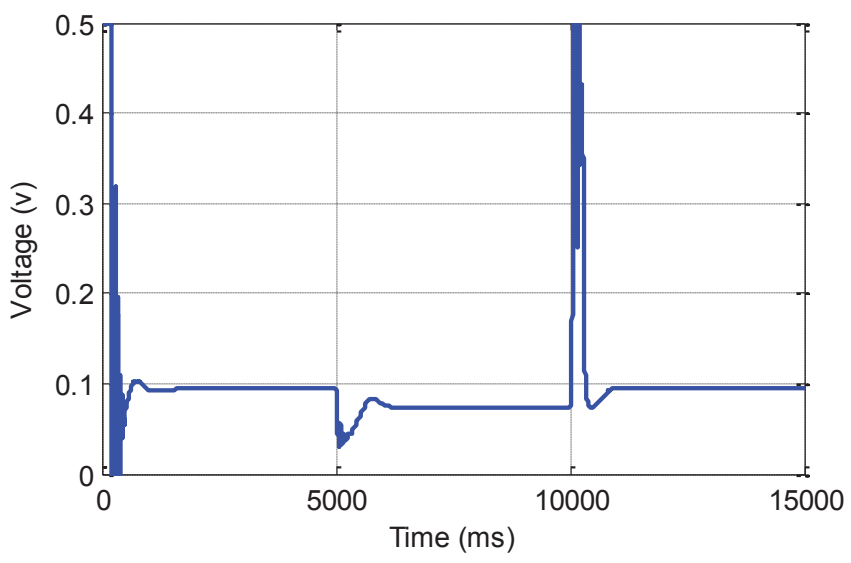

Figure 6. Controller command to the proportional valve in regulation under low wind speed disturbances.

\section{B. Control under High Wind Speed Disturbances}

In this section, the controller performance is tested under high wind speed fluctuations. For this simulation, a high initial wind speed is applied to the system, following a high step variation during the run. The controller actuates the proportional valve properly to compensate for applied high wind speed fluctuations on the pump. Fig. 7 depicts the wind fluctuations exerted to the control system. Regulation response of the system is shown in Fig. 8 and Fig. 9. Finally, Fig. 10 illustrates the control command applied to the proportional valve by the controller. Reponses of this simulation shows a reasonable performance for the control system.

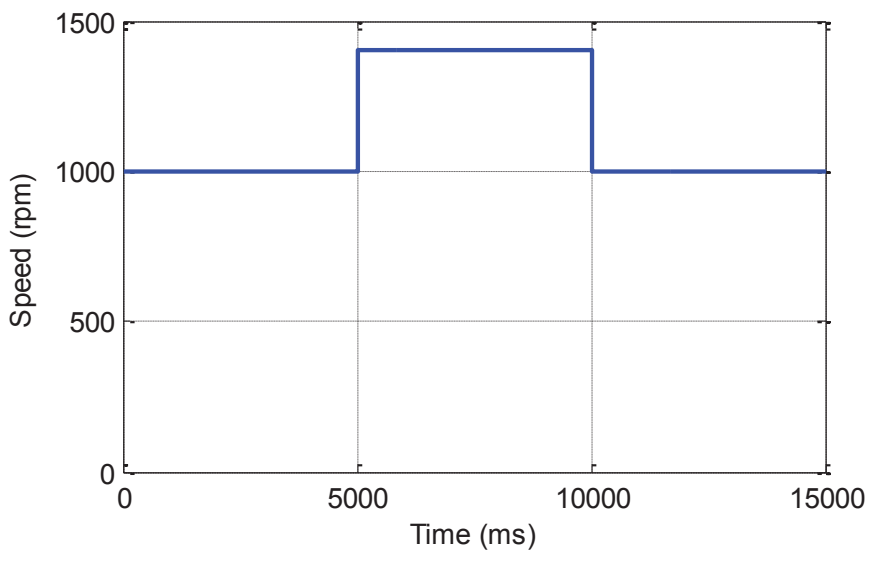

Figure 7. Pump speed variations applied to regulation under high wind speed disturbances.

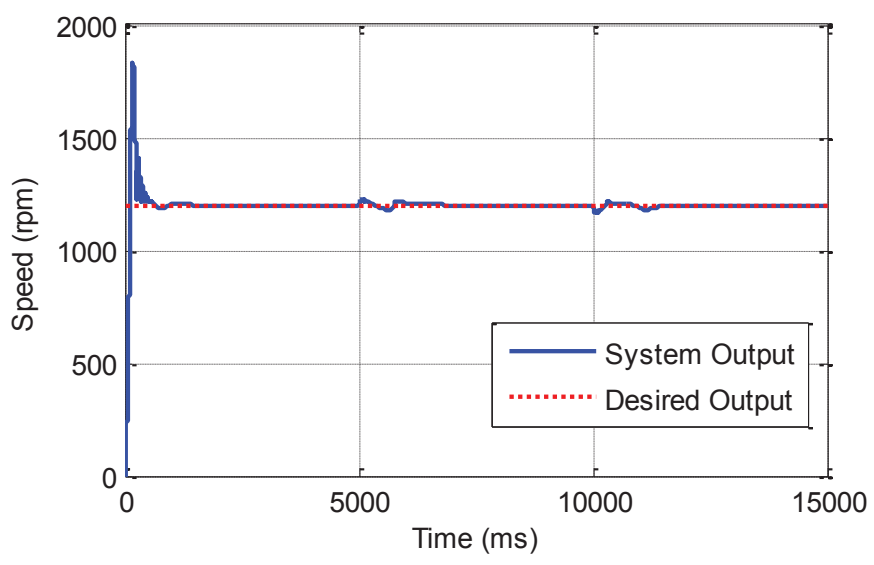

Figure 8. Regulation response of the system under high wind speed disturbances.

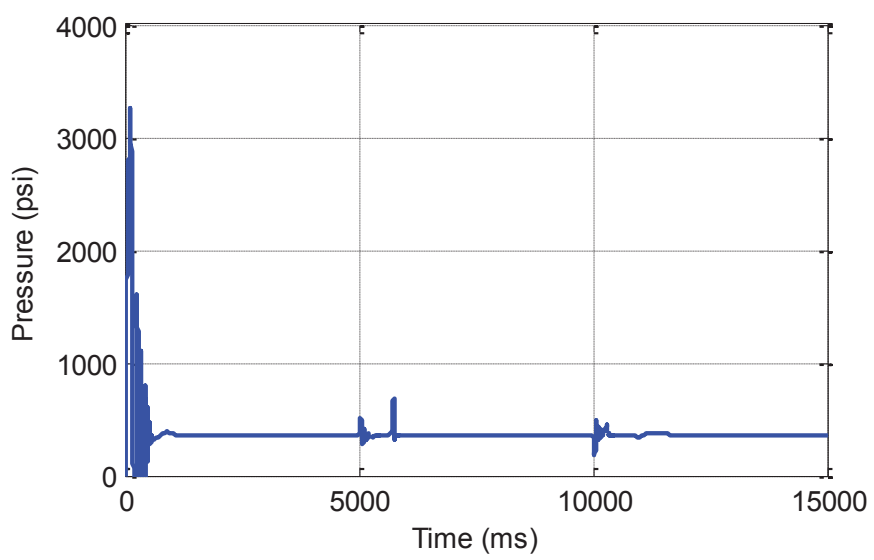

Figure 9. Motor A pressure in regulation under high wind speed disturbances. 


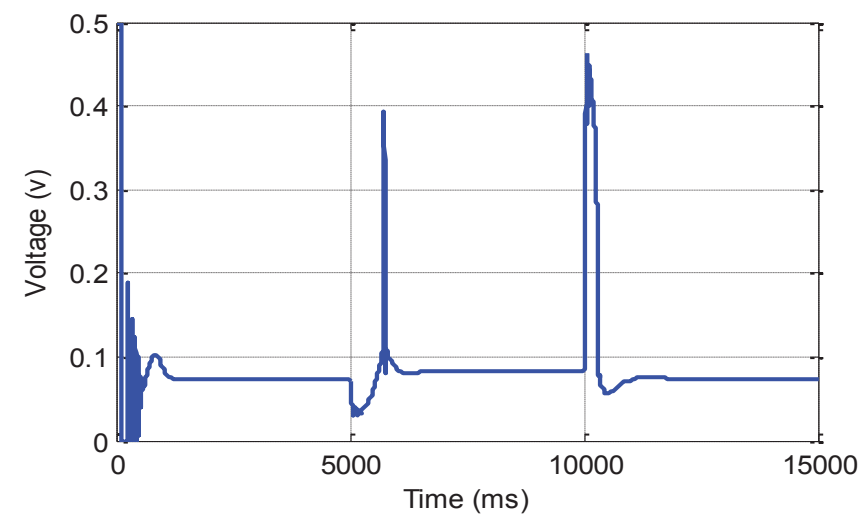

Figure 10. Controller command to the proportional valve in regulation under high wind speed disturbances.

\section{CONCLUSION}

This paper developed a control system for the nonlinear model of hydraulic wind power transfer systems. To maintain a fixed frequency electrical voltage by the system, the generator should remain at a constant rotational speed. The fluctuating wind speed from the upstream applies considerable disturbances on the system. A controller was designed and implemented to regulate the flow in the proportional valve and as a consequence the generator maintains its constant speed compensating for wind speed disturbances. According to the results from the simulations of the hydraulic wind power transfer system, it can be concluded that the control system is working perfectly under low wind speed and high wind speed fluctuations. However, increasing the number of the hydraulic components exert more nonlinearities to the system which may require for an advanced controller such as adaptive controller [29].

\section{ACKNOWLEDGMENT}

This work was published from the Inaugural Grant Award through the Vibration Institute.

\section{REFERENCES}

[1] A. Izadian, N. Girrens, and P. Khayyer, "Renewable Energy Policies: A Brief Review of the Latest US and EU Policies," Industrial Electronics Magazine, IEEE, vol. 7, pp. 21-34, 2013.

[2] S. Eriksson, H. Bernhoff, and M. Leijon, "Evaluation of different turbine concepts for wind power," Renewable and Sustainable Energy Reviews, vol. 12, pp. 1419-1434, 2008.

[3] M. Vaezi and A. Izadian, "Multiple-model adaptive estimation of a hydraulic wind power system," in Industrial Electronics Society, IECON 2013-39th Annual Conference of the IEEE, 2013, pp. 2111-2116.

[4] A. Izadian, "Central Wind Turbine Power Generation," ed: Google Patents, 2010.

[5] S. Hamzehlouia, A. Izadian, A. Pusha, and S. Anwar, "Controls of hydraulic wind power transfer," in IECON 2011-37th Annual Conference on IEEE Industrial Electronics Society, 2011, pp. 24752480.

[6] M. Vaezi, A. Izadian, and M. Deldar, "A model linearization technique for hydraulic wind power systems," in Power and Energy Conference at Illinois (PECI), 2014, 2014, pp. 1-5.

[7] S. Hamzehlouia and A. Izadian, "Adaptive speed regulation of gearless wind energy transfer systems," in IECON 2012 - 38th Annual Conference on IEEE Industrial Electronics Society, 2012, pp. 21622167.
[8] M. Vaezi, H. Jazeh, F. Samavati, and S. A. A. Moosavian, "Singularity analysis of $6 \mathrm{DOF}$ Stäublic TX40 robot," in Mechatronics and Automation (ICMA), 2011 International Conference on, Chengdu, China, 2011, pp. 446-451.

[9] J. Thomas, S. Olaru, J. Buisson, and D. Dumur, "Robust model predictive control for piecewise affine systems subject to bounded disturbances," in Analysis and Design of Hybrid Systems, 2006, pp. 329334.

[10] H. E. S. Jazeh, M. Vaezi, F. C. Samavati, and S. A. A. Moosavian, "The robustness analysis of two motion control algorithms for Stäubli TX40 robot in object manipulation task," in Mechatronics and Automation (ICMA), 2011 International Conference on, 2011, pp. 2165-2170.

[11] S. Hamzehlouia and A. Izadian, "State-space representation of a hydraulic wind power transfer," in Electro/Information Technology (EIT), 2012 IEEE International Conference on, 2012, pp. 1-6.

[12] A. Pusha, A. Izadian, S. Hamzehlouia, N. Girrens, and S. Anwar, "Modeling of gearless wind power transfer," in IECON 2011-37th Annual Conference on IEEE Industrial Electronics Society, 2011, pp. 3176-3179.

[13] M. Vaezi, A. Izadian, and M. Deldar, "Adaptive Control of a Hydraulic Wind Power System Using Multiple Models," in Industrial Electronics Society, IECON 2014-40th Annual Conference of the IEEE, 2014.

[14] A. Izadian, S. Hamzehlouia, M. Deldar, and S. Anwar, "A Hydraulic Wind Power Transfer System: Operation and Modeling," Sustainable Energy, IEEE Transactions on, vol. 5, pp. 457-465, 2014.

[15] M. Vaezi, M. Deldar, and A. Izadian, "Hydraulic Wind Power Plants: Nonlinear Model of Low Wind Speed Operation," Control Systems Technology, IEEE Transactions on, 2014.

[16] S. Hamzehlouia and A. Izadian, "Nonlinear state space model of a hydraulic wind power transfer," in IECON 2012 - 38th Annual Conference on IEEE Industrial Electronics Society, 2012, pp. 10981103.

[17] S. Hamzehlouia and A. Izadian, "Modeling of hydraulic wind power transfers," in Power and Energy Conference at Illinois (PECI), 2012 IEEE, 2012, pp. 1-6.

[18] M. Deldar, A. Izadian, M. Vaezi, and S. Anwar, "Modeling of a Hydraulic Wind Power Transfer Utilizing a Proportional Valve," Industry Applications, IEEE Transactions on, Accepted, 2014.

[19] M. Vaezi and A. Izadian, "Piecewise Affine System Identification of a Hydraulic Wind Power Transfer System," Control Systems Technology, IEEE Transactions on, Accepted, 2014.

[20] L. Shi, Z. Xu, C. Wang, L. Yao, and Y. Ni, "Impact of Intermittent Wind Generation on Power System Small Signal Stability, p. 161, 2011.

[21] S. Gao and N. Zhang, "A review of different methodologies for solving the problem of wind power's fluctuation," in Sustainable Power Generation and Supply, 2009. SUPERGEN'09. International Conference on, 2009, pp. 1-5.

[22] P. Sorensen, N. A. Cutululis, A. Vigueras-Rodríguez, L. E. Jensen, J. Hjerrild, M. H. Donovan, et al., "Power fluctuations from large wind farms," Power Systems, IEEE Transactions on, vol. 22, pp. 958-965, 2007.

[23] K. Ogata and Y. Yang, "Modern control engineering," 1970.

[24] M. Deldar, A. Izadian, S. Anwar, and M. Vaezi, "Modeling of a Hydraulic Wind Power Transfer Utilizing a Proportional Valve," Industry Applications, IEEE Transactions on, Accepted, 2014.

[25] M. Gorbeshko, "Development of mathematical models for the hydraulic machinery of systems controlling the moving components," Hydrotechnical Construction, vol. 3, 1997.

[26] H. E. Merritt, Hydraulic control systems: John Wiley \& Sons, 1967.

[27] E. C. Fitch, Hydraulic component design and selection: Bardyne. Incorporated, 2004.

[28] J. F. Blackburn, Fluid power control: Mit Press, 1969.

[29] A. Edalatnoor, A. Izadian, and M. Vaezi, "Indirect adaptive control of droplet dispensing in digital microfluidic systems," in Industrial Electronics Society, IECON 2013-39th Annual Conference of the IEEE, 2013, pp. 3580-3585. 